\title{
How pedophilic men think about adult-child sex: effects of child gender and physical maturity
}

\section{Sara Jahnke \& Agustín Malón}

To cite this article: Sara Jahnke \& Agustín Malón (2018): How pedophilic men think about adult-child sex: effects of child gender and physical maturity, Psychology, Crime \& Law, DOI: 10.1080/1068316X.2018.1503665

To link to this article: https://doi.org/10.1080/1068316X.2018.1503665

Accepted author version posted online: 20

Jul 2018.

Published online: 25 Jul 2018.

Submit your article to this journal ๔

Llll Article views: 29

View Crossmark data $\asymp$ 


\title{
How pedophilic men think about adult-child sex: effects of child gender and physical maturity
}

\author{
Sara Jahnke a and Agustín Malón ${ }^{b}$ \\ ${ }^{a}$ Department of Research Synthesis, Intervention and Evaluation, Friedrich-Schiller-University Jena, Jena,

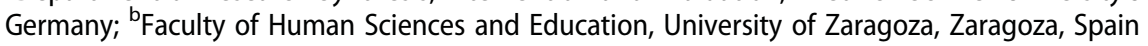

\begin{abstract}
To date, very little research has tackled whether pedophilic men's attitude towards adult-child sex depends on characteristics of the adult or the child involved in such acts. This study examines the effect of the child's gender (male vs. female) and physical maturity (pre-pubescent vs. early pubescent) on the moral evaluation of apparently noncoercive adult-child sex in a $2 \times 2$ factorial online vignette experiment. One hundred eighty-three English-speaking pedophilic men rated their agreement with moral arguments on the Immoral Sex Scale, as well as whether they believed this behavior to be typical for a child. The results revealed considerable inter-individual differences, with about one third showing restrictive moral attitudes. Contrary to our expectations, gender and physical maturity neither affected the perceived morality of the sexual act, nor beliefs about the representativeness of the child's behavior. However, when controlling for confounds, pedophilic men believed that boys were more likely to willingly engage in adult-child sex. Furthermore, participants with stronger liberal attitudes were found to be more likely to defend the sexual act, as were participants with a preferential interest in pre-pubescents. There was no link between attitudes towards adult-child sex and sexual offending, replicating the non-associations reported in previous community surveys.
\end{abstract}

ARTICLE HISTORY

Received 19 January 2018 Accepted 12 July 2018

\section{KEYWORDS}

Pedophilia; child sexual abuse; attitudes; survey

\section{Introduction}

People with pedophilia, those who are sexually interested in children before puberty and desire sexual activities with them (e.g. Beier et al., 2009), are more likely to have permissive attitudes regarding the morality of adult-child sex than people without such interests (Bailey, Bernhard, \& Hsu, 2016). Yet, despite common misperceptions, the idea that most pedophilic individuals approve of all sexual acts between adults and children, especially if they involve coercion of an unwilling child, is not supported by evidence (Holt, Blevins, \& Burkert, 2010; Stermac \& Segal, 1989). In fact, past research strongly indicates that men with a sexual interest in children are a heterogeneous population with a rich and diverse discourse about the morality of this peculiar sexual desire and

CONTACT Sara Jahnke sara.jahnke@uni-jena.de E Department of Research Synthesis, Intervention and Evaluation, Friedrich-Schiller-University Jena, Humboldstraße 26, JenaD-07743, Germany

(c) 2018 Informa UK Limited, trading as Taylor \& Francis Group 
corresponding sexual acts (Spriggs, Cohen, Valencia, Zimri, \& Galynker, 2018). Hence, a more in-depth knowledge of how, when, and why pedophilic men come to consider adult-child sex as abusive, illegitimate, and harmful (or, conversely, beneficial or at least inconsequential) could inform therapeutic interventions with pedophilic men who are at risk of sexual (re-) offending.

While variance in sexual morality judgments may be attributable to inter-individual differences like political orientation, aspects of the child and the adult involved (e.g. the child's reaction, the adult's social position), as well as the context (e.g. the emotional quality of the relationship) might also systematically affect ratings of the moral permissiveness of adult-child sex. Therefore, in the current article, we investigated whether two defining variables of the child, that is, his or her gender and sexual maturity, influenced pedophilic men's perception of the moral legitimacy of an adult man having sex with him or her, using vignettes that attempt to capture the 'ideal of sex between a caring adult and a consenting child' (Jahnke, Schmitt, \& Malón, 2017, 'introduction,' para. 1). Note that while the assumption that a child is able to give consent to sexual activities is not in line with current social and legal norms (Spriggs et al., 2018), this view is often expressed in online communities for pedophilic men (e.g. Holt et al., 2010).

\section{Attitudes towards adult-child sex among pedophilic men}

Since the 1980s, there has been a growing interest in how child sexual offenders (50\% of whom can be expected to have corresponding sexual interests in children, Seto, 2007) think and feel about sexual abuse (e.g. Abel et al., 1989; Gannon \& Polaschek, 2006; Ward \& Keenan, 1999; Ward \& Siegert, 2002). Based on the assumption that pro-offense attitudes contribute to criminal behavior, understanding offenders' perceptions of adult-child sex held a great promise: being able to deter offenders from committing further sexual offenses against children (Howitt \& Sheldon, 2007; Murphy, 1990), or to prevent first-time offenses with cognitive interventions (Beier, 2016). In fact, researchers could establish that attitudes that legitimize sexual offending were associated with higher recidivism risks among offenders who have been convicted for such acts (e.g. Banse, Koppehele-Gossel, Kistemaker, Werner, \& Schmidt, 2013; Helmus, Hanson, Babchishin, \& Mann, 2013). Yet, whether or not a reduction of pro-offense attitudes among sexual offenders actually decreases recidivism risk remains unclear (Banse et al., 2013). Recent research on the links between moral attitudes towards adult-child sex and sexual offenses involving children among non-forensic samples of minor-attracted men have furthermore produced mixed results. While Cohen, Ndukwe, Yaseen, and Galynker (2017) and Jahnke, Schmidt, Geradt, and Hoyer (2015) reported a small association between pro-offense attitudes and prior sexual offenses involving children, other researchers could not detect such links in their data (Bailey et al., 2016; Jahnke et al., 2017).

As these findings indicate, pro-offense cognitions and their role in sexual offending are not well understood. Also, as the definition of offense-supportive attitudes is heterogeneous in meaning and conceptualized with reference to legal or normative standards, they are not causal agents, even though they may be linked to psychological or psychopathological processes (e.g. attention, intimacy, or self-regulation processes, Ward \& Fortune, 2016). Another reason that might complicate research on attitudes related to adult-child sex is researchers' tendency to address this issue in terms that do not 
capture the complexity of the moral debate on adult-child sex- a discourse which appears to be especially rich and diverse among non-forensic communities of pedophilic men (Goode, 2009; Holt et al., 2010; Jahnke et al., 2017). Thus, as we will argue throughout this article, an examination of key variables that may play a role in the moral evaluation of adult-child sex based on surveys and experimental paradigms among non-forensic samples of pedophilic men is needed to further unveil how pedophilic men come to consider sexual acts between adults and children as good or bad.

\section{The importance of sexual maturity and gender for moral reasoning}

In our liberal culture, the consent of the participants, together with the absence of objective harm and abuse of power, are the most relevant arguments in defining a sexual morality based on Kantian and utilitarian principles (Finkelhor, 1979; Malón, 2015, 2017; Schmidt, 2002). In general, it has been stated that these modern principles to judge sexual behavior are conductive to a more liberal or permissive sexual culture, which allows individuals to realize their personal ideals of sexual happiness and wellbeing (Benn, 1999; Seidman, 1992). This may lead to accepting or even defending a naturalist conception of sex as a personal and pleasurable experience without too much transcendence in moral and social terms (Davis, 1983).

In accordance with this ethical perspective, where the morality of a sexual act is basically limited to its permissibility and not its moral value or worthiness, elements as gender or physical characteristics of participants would be irrelevant. It's the rational person who can consent or not, and who is harmed or abused, making his or her intellectual capacities, as well as other non-constitutive elements such as economic power, autonomy, and sexual knowledge the relevant aspects for moral judgment. Menarche, breast buds, body hair or other corporal signs of sexual maturity, which used to be important signals in the past or in other cultures (Frayser, 1985), are now apparently less relevant to sexual morality, while a person's age, as a sign of psychological maturity and reason responsiveness, has become the main criteria to judge the permissibility of sexual acts, paralleling similar debates on the importance of a minor's ability to give informed consent in other areas of life (e.g. medical treatment or participation in research, Bruzzese \& Fisher, 2003; Kuther, 2003). Hence, in Western societies we are witnessing a growing gap between physical and socio-legal definitions of maturity: while minors enter puberty at a younger age than in the past, legislations tend to increase the legal age of consent (Killias, 2000).

Still, it is possible that the child's gender and physical maturity can shape how adultchild sex is perceived in ways that respondents might not be consciously aware of. Corporal traits indicating sexual maturity or immaturity may influence moral judgments as they provide information not only about cognitive capacities of participants, but also of the normality of an erotic interest, the convenience of a sexual behavior (i.e. penetrative/non penetrative), and the 'real' value and significance of an erotic bond. Beyond bodily changes, puberty is associated with tremendous psychosexual development (Herdt \& McClintock, 2000), involving the awakening of sexual interests in other people, the desire for 'being desired' by others, awareness of sexual arousal, and experimentation with masturbation and non-penetrative partnered sexual activities (while coitus appears to be relatively rare among adolescents aged 15 years or younger, Fortenberry, 2013). 
As these reported physical and psychological changes make children more adult-like, moral arguments against adult-child sex may apply less to adolescence compared to childhood. In fact, experimental vignette studies have repeatedly shown that older children or adolescents who have been abused are more likely to be perceived as responsible for the abuse (Back \& Lips, 1998).

Similarly, different 'ideals' of masculinity and femininity that are strongly connected to sexual behaviors and norms still exist (e.g. passive vs. active) and may elicit different evaluations of the same act depending on the gender of the person, contributing to a so-called double standard, that is, the 'belief or attitude that a specific sexual behavior, or all sexual behavior, is more acceptable for persons of one sex, usually males, than persons of the other sex' (Bullough \& Bullough, 1994, p. 173; but note that some authors have challenged the existence of a double standard, at least in liberal universtity populations, see e.g. Marks \& Fraley, 2005). Furthermore, a cultural bias against non-heterosexual orientations (Herek, 2004) might lead to more negative reactions towards adult-child sex when the child and the adult are of the same sex (Herek, 2004). In line with this, past research shows that samesex encounters between adults and children were judged especially harmful by college students (Broussard \& Wagner, 1988; Broussard, Wagner, \& Kazelskis, 1991) and that adults were rated as less responsible when the child was male (Broussard \& Wagner, 1988), but only when the child was portrayed as acting in an encouraging manner.

However, note that the studies on moral evaluations of adult-child sex have been conducted among people from the general population who are statistically unlikely to have a sexual interest in children. Hence, we still know very little about whether the gender of a child would have an effect on pedophilic men's perception of adult-child sex in much the same way. As pedophilic men are, however, part of the same culture and therefore likely to be aware of the common moral discourse on adult-child sex, we would hypothesize that factors like the child's gender or physical maturity play a role in pedophilic men's moral perception of adult-child sex. Using fictitious material to systematically manipulate different aspects of a sexual scenario (e.g. a child's age, sex, or reaction) represents an intriguing, yet rarely used, method to study attitudes among pedophilic men. For instance, Stermac and Segal (1989) manipulated the type of sexual contact between an adult and a child (e.g. touching, ejaculation) and the child's response (e.g. smiling, passive) using different vignettes. The authors could show that child sexual offenders endorsed a wider range of sexual behaviors with children as acceptable than other offender and non-offender groups and that their perception only changed in response to an unambiguously negative reaction from the child (i.e. crying).

\section{Goals and hypotheses of the current study}

We predict that the child's gender has an influence on whether or not the sexual act is perceived as immoral. However, note that we cannot make any predictions regarding the direction of this effect. Sex between boys and men could be perceived as rarer and more deviant and harmful than heterosexual sex. Yet, in line with the idea that promiscuity is more desirable for men than for women, adult-child sex (that the child appears to engage in willingly) might also be judged as less harmful or even beneficial for male compared to female children. We will also explore whether child gender influences pedophilic men's Representativeness Beliefs, that is, beliefs that this child would actually engage in 
adult-child sex in the way it is presented in the scene, or whether such a behavior is more typical for either boys or girls.

Given that children who are more physically mature can be expected to be less sexually naïve, we hypothesize that moral attitudes towards adult-child sex are more permissive when the child in the vignette is in the early stages of puberty (as opposed to the pre-pubertal stage). Furthermore, we expect participants to show lower Representativeness Beliefs when the child is less sexually mature.

As liberalism is concerned with the 'acceptance and/or affirmation of individual sexual freedom,' and conservatism with upholding conventional norms and traditions, we expect liberal views to be associated with more permissive sexual attitudes (Guerra, Gouveia, Sousa, Lima, \& Freires, 2012, p. 1028). To contribute to the ongoing debate about the links between cognitions about adult-child sex and criminal behavior, we will look at whether agreement with moral arguments against adult-child sex or beliefs about the likelihood of children willingly engaging in sex with adults is linked to reports of past sexual offences. We will furthermore explore links between Immoral Sex, Representativeness Beliefs, and sociodemographic information, and sexual age and gender preferences.

\section{Method}

\section{Participants}

Power analysis were conducted in G*Power 3 (Faul, Erdfelder, Lang, \& Buchner, 2007) with an alpha of .05 , a beta of .20 and a medium-sized effect $(f=.25)$. Based on these parameters, the sample size was determined to be 180 . As we expected that we would have to discard some cases because of too many missing data or for not meeting our inclusion criteria (i.e. male gender), we decided to keep collecting data as long as there was attrition, leading to a total of 191 completed surveys. Twenty-two participants were excluded at the beginning of the survey based on their lack of sexual interest in pre-pubescents (all survey participants had to indicate at least a moderate level of pedophilic interests, defined as responses of ' 5 ' as the midpoint of the sexual attraction scale for prepubescent boys, girls, or both, see Instruments for a description of the sexual attraction ratings). Furthermore, eight participants were excluded after data collection because they indicated their gender as 'female' or 'other.' Thus, the final sample consisted of 183 pedophilic men. Missing data were rare $-97 \%$ returned complete questionnaires and we recorded between 1 and 2 missing values for the rest of the sample (e.g. because participants did not report their age). Although these missing data were likely to be deliberate (as participants received notifications for unanswered items), we opted for pairwise instead of listwise deletion due to their small number. Participants' ages ranged between 18 and 70 $(M=33.61, S D=12.47)$. Eleven percent reported to have children, with $6.0 \%$ stating that their children were 14 years old or younger. The average person in this sample was politically liberal rather than conservative $(M=7.63, S D=2.53$ on a Likert-type scale from 1 [conservative] to 10 [liberal]), and $60.1 \%$ reported to hold an Associate or Bachelor's degree or higher. Regarding criminal offenses, a few participants indicated at least one conviction for child pornography offenses $(8.7 \%)$, child sexual abuse $(5.5 \%)$, or other sexual offenses (2.7\%). Eighty-seven percent reported to have never committed sexual crimes involving children (i.e. child sexual abuse and/or child pornography offenses). 


\section{Procedure}

Participants were recruited via websites for the minor-attracted community (boylandonline.com, boychat.org, viped.org). Following a link, they were redirected to the questionnaires which were administered via the multi-language online survey program SoSci Survey (Leiner, 2014) that is designed for scientific surveys and provides high standards of data protection (e.g. no recording of IP addresses, SSL Encryption). At the end of the survey, participants were asked to share the study link with other pedophilic men that they might know. Participants were randomly assigned to either a 'pre-pubertal girl,' 'early to mid-pubertal girl,' 'pre-pubertal boy,' or 'early to mid-pubertal boy' condition and were presented vignettes (see Appendix) featuring a boy or girl before or in the early stages of puberty, depending on the experimental condition. In all four vignettes the sex is portrayed as nonpenetrative and with no apparent signs of force or manipulation.

\section{Measures}

All instruments are presented in the same order that they were used within the study. It was generally possible for subjects to skip questions (unless needed to assess inclusion criteria, i.e. participants' gender, sexual interests, and agreement with the informed consent statement), but they would receive notifications highlighting missing responses to ensure that missing values were deliberate. At the end of the survey, we collected sociodemographic information (e.g. age, gender, educational level). Cronbach's alpha for all scales can be found in Table 1 .

\section{Self-reported pedophilic, hebephilic, and teleiophilic interests}

In this study, we used a novel way of assessing chronophilic orientations. Instead of using age cutoffs, which are an unreliable indicator of puberty, we asked for sexual attraction to people of different genders, and levels of physical maturity (see Appendix). The stages of physical maturation have been described by Tanner (e.g. Marshall \& Tanner, 1969, 1970) on a five-stage scale that later came to be named after this author. Tanner stage 1 corresponds to the pre-pubertal stage and is characterized by a lack of signs of sexual maturation. Tanner stage 2 marks the onset of pubertal changes, usually beginning with a sparse growth of downy pubic hair (for both genders), the appearance of breast buds (among girls) and the enlargement of testes (among boys). Growth of pubic hair typically starts between 10 and 11 years for girls and 11 and 12 years for

Table 1. Means and standard deviations for the dependent variables.

\begin{tabular}{lcccc}
\hline & $\begin{array}{c}\text { Pre-pubescent girl } \\
(n=43)\end{array}$ & $\begin{array}{c}\text { Pubescent girl } \\
(n=48)\end{array}$ & $\begin{array}{c}\text { Pre-pubescent boy } \\
(n=44)\end{array}$ & $\begin{array}{c}\text { Pubescent boy } \\
(n=48)\end{array}$ \\
\cline { 2 - 5 } Dependent Variables (Cronbach's a) & $M(S D)$ & $M(S D)$ & $M(S D)$ & $M(S D)$ \\
\hline Immoral Sex (.96) & $3.45(1.54)^{\mathrm{a}}$ & $3.53(1.80)$ & $3.01(1.61)$ & $3.47(1.60)^{\mathrm{b}}$ \\
Indirect Harm (.56) & $5.90(0.90)$ & $5.30(1.24)$ & $5.47(1.38)$ & $5.53(1.14)^{\mathrm{a}}$ \\
Representativeness Beliefs (.89) & $4.11(1.73)$ & $4.17(1.66)$ & $4.89(1.54)$ & $4.15(1.62)$ \\
\hline
\end{tabular}

Note: All questionnaires are rated on a 7-point-Likert scale from 1 to 7 .

ane missing value.

$b_{\text {two missing values. }}$ 
boys, with non-Hispanic black girls and boys showing earlier signs of maturation (Sun et al., 2002). Sexual maturation is completed at Tanner stage 5, which is reached between 15 and 17 (Sun et al., 2002). For each group, we offered a short description of their physical characteristics (e.g. boys who show no signs of sexual maturity like pubic hair or a larger penis or scrotum for boys before puberty). Participants rated their degree of attraction to each group on a 10-point Likert scale from no sexual interest (1) to maximum sexual interest (10).

\section{Representativeness beliefs}

While instructions in Jahnke et al. (2017) read that participants should rate the vignette irrespective of whether they believed the scenario to be common, participants in the current study were asked whether they believed the reaction of the child in the vignette to be typical, common, or believable (instruction: To what extent do you think that the (girl's/boy's) reaction to the sexual activity is typical, common, or believable for (girls/ boys) of the same age and level of sexual maturity?). Participants were asked to respond on a 7-point Likert scale (very typical - very untypical, very common - very uncommon, very believable - very unbelievable). This was done to test the link between adult-child sex attitudes and sexual offending behavior more rigorously compared to previous authors, as pedophilic individuals might find the fictitious scenario unproblematic but highly uncharacteristic. We recoded the scale so that higher scores represent higher beliefs that the reaction is typical.

\section{Immoral sex scale}

Participants rated the 20 items of the Moral Attitudes towards Adult-Child Sex Scale with respect to the vignette from 1 (do not agree) to 7 (fully agree, original scale from Jahnke et al., 2017). In the present study, we used the English version of the scale and modified it slightly by exchanging the word 'child' with 'boy' or 'girl,' depending on the vignette preceding it, and setting all pronouns to correspond with the gender of the vignette (i.e. 'her' or 'his,' 'he or she,' 'himself or herself'). Subscales of the Moral Attitudes scale included Direct Harmfulness (e.g. 'It is likely that the (girl/boy) will suffer psychological harm as a result of the sexual contact'), Indirect Harmfulness ('The sexual contact was problematic for the (gir//boy) because society rejects sex with children'), Non-consent ('The (girl/boy) was probably as competent as the adult to make decisions about participating in sexual contacts.'), Exploitation ('Consciously or subconsciously, the adult used the (girl/boy) for his own pleasure and interests'), and Incompatibility of Adults' and Children's Sexualities ('The psychological needs of the (girl/boy) and the adult were too different to make a healthy sexual relationship possible.'). As in Jahnke et al. (2017), all subscales (with the exception of Indirect Harm) showed high intercorrelations (between $r=.85$ and .89 ). The combined score of the subscales Direct Harmfulness, Non-consent, Exploitation, and Incompatibility of Adults' and Children's Sexualities (from here on referred to as Immoral Sex score) proved to be highly internally consistent. The Immoral Sex score assesses the moral attitude that adult-child sex is inherently bad based on agreement with the four aforementioned moral arguments. As the Indirect Harmfulness subscale did not reach the proposed threshold of $a=.70$ (see Table 1), it will be used for descriptive purposes only. 


\section{Social desirability scale}

We used a short 8-item adapted Social Desirability Scale (Ray, 1984) to identify response tendencies indicating the wish to present oneself in an unrealistically positive light. Higher Social Desirability scores reflect endorsement of a higher number of socially desirable, yet unlikely, statements (e.g. 'Are you quick to admit making a mistake?', but note that the scale also uses inversely coded items such as 'Have you sometimes taken unfair advantage of another person?') and responses are scored from False (1) to True (2), as opposed to the original scale that included a neutral category. Reversely coded items earned scores of 2 and 1 , respectively.

\section{Qualitative data}

Participants were encouraged to give feedback at the end of the survey ('If you noticed anything either negative or positive about this survey that caught your attention, please feel free to drop us a note in this field [but please do not include information that could make you personally identifiable like your name or address]'). About half of the participants used to opportunity to share their thoughts and feelings about the research.

\section{Results}

\section{Preferential sexual interests within the sample}

By subtracting the maximum value of sexual attraction to either girls or boys from the maximum value of sexual attraction to any other (hebephilic or teleiophilic) category, we categorized $67.1 \%$ of the sample as having a pedophilic preference (i.e. a sexual interest in pre-pubescents that is higher or equal to other sexual interest in people from the hebephilic or teleiophilic categories). Only four participants (2.4\%) reported a stronger interest in adults compared to the pedophilic and hebephilic categories (note that these cases were retained in the analyses because they reported their sexual attraction to children or adolescents to be at least moderately strong and almost on par with their sexual attraction to adults, meaning there was only a one-point difference on the 10point sexual attraction scale). Eighty-two percent of the sample had a non-heterosexual preference, that is, reported a sexual attraction to male partners that was higher or equal to their sexual attraction in female partners.

\section{Ratings on the immoral sex and the representativeness beliefs scale}

Means and standard deviations of the dependent variables are displayed in Table 1. Most pedophilic men $(67 \%)$ in this sample generally disagreed that adult-child sex is immoral (e.g. scored below the midpoint of the Immoral Sex scale), while about one third (31\%) generally agreed with arguments against adult-child sex (note that $2 \%$ achieved scores of 4 , indicating indifference). With only $9 \%$ scoring lower than the midpoint of the Indirect Harm scale, there was general agreement (88\%) that the child would have to fear stigmatization from society due to his or her sexual activities. Likewise, $55 \%$ and $37 \%$ gave responses above or below the midpoint of the Representativeness Beliefs scale, respectively. Hence, slightly more than half of our participants agreed that the vignette described 
a typical child, which indicates that most participants believed that children in general would act in the described sexual manner.

\section{Effects of gender and physical maturity}

As expected due to randomization, participants assigned to different vignettes did not differ with respect to rates of pedophilic preference $\left(x^{2}=4.15, p=.246\right)$, non-heterosexual orientation $\left(X^{2}=1.29, p=.731\right)$, social desirability $(F(3,179)=.17, p=.919)$, education $\left(X^{2}=\right.$ 2.37, $p=.500)$, political orientation $(F(3,179)=.15, p=.929)$, having children $\left(x^{2}=0.79\right.$, $p=.852)$, having committed sexual offenses involving children $\left(x^{2}=6.15, p=.105\right)$, and age $(F(3,177)=.54, p=.653)$. In a $2 \times 2$ factorial analysis of variance (ANOVA), we detected no main effects for gender and physical maturity and no gender $x$ physical maturity interaction effect (see Table 2). That means that pedophilic men did not rate the morality of non-coercive sexual acts between adults and children differently when the child was a boy (instead of a girl) and when he or she had not yet entered puberty (as opposed to being in the early stages of puberty), nor did it affect the belief that children of the described maturity level or gender would act as portrayed in the vignette.

\section{Correlates of immoral sex and representativeness beliefs}

Based on correlational analyses (see Table 3), we detected significant links between the dependent variables and pedophilic preference, non-heterosexual orientation, and political orientation. Participants with preferential pedophilic interests (i.e. a stronger or equally strong sexual interest in pre-pubescents compared to pubescent or adults) scored lower on Immoral Sex and higher on Representativeness Beliefs, showing more permissive attitudes than participants who had a dominant sexual interest in more mature people, and a stronger belief that most children would willingly engage in sex with adults. Likewise, people with a primary non-heterosexual interest agreed more with arguments on the Immoral Sex scale and less with the items on the Representativeness Scale, which means that they showed more permissive attitudes. Yet, subsample analyses revealed that homosexual preference was significantly linked to lower ratings on Immoral Sex $\left(r_{\text {spearman }}=-.31, p=.003\right)$ and higher Representativeness Beliefs $\left(r_{\text {spearman }}=.25, p=.018\right)$ only when the child was a boy and not when the child was a girl $\left(r_{\text {spearman }}=.05\right.$, $p=.661$ for Immoral Sex, $r_{\text {spearman }}=.06, p=.553$ for Representativeness Beliefs, all tests

Table 2. Immoral sex and representativeness beliefs depending on gender and maturity, including analysis of variance test statistics.

\begin{tabular}{|c|c|c|c|c|c|c|c|c|}
\hline \multirow{2}{*}{$\begin{array}{l}\text { Dichotomous variables and } \\
\text { coding schemes }\end{array}$} & \multicolumn{4}{|c|}{ Immoral Sex $(N=180)$} & \multicolumn{4}{|c|}{ Representativeness Beliefs $(N=183)$} \\
\hline & $M(S D)$ & $F$ & $p$ & $\eta^{2}$ & $M(S D)$ & $F$ & $p$ & $\eta^{2}$ \\
\hline Gender & & 1.06 & .306 & .01 & & 2.52 & .114 & .01 \\
\hline 1 Female & $3.50(1.68)$ & & & & 4.14 & & & \\
\hline 2 Male & $3.25(1.61)$ & & & & 4.51 & & & \\
\hline Maturity & & 1.20 & .276 & .01 & & 1.98 & .162 & .01 \\
\hline 1 Pre-pubertal & $3.23(1.59)$ & & & & 4.51 & & & \\
\hline 2 Pubertal & $3.50(1.70)$ & & & & 4.16 & & & \\
\hline Gender $\times$ Maturity & & .59 & .444 & .00 & & 2.71 & .102 & .02 \\
\hline
\end{tabular}

Note: $d f 1=1, d f 2=176$ for Immoral Sex as outcome, $d f 2=179$ for Representativeness Beliefs as outcome. 
Table 3. Pearson correlation matrix.

\begin{tabular}{|c|c|c|c|c|c|c|c|c|c|}
\hline & IS & $\mathrm{RB}$ & PP & NO & SD & $\mathrm{E}$ & $\mathrm{PO}$ & $\mathrm{C}$ & 0 \\
\hline Immoral Sex (IS) & - & & & & & & & & \\
\hline Representativeness Beliefs (RB) & $-0.69 * *$ & - & & & & & & & \\
\hline Pedophilic Preference (PP) ${ }^{\mathrm{b}}$ & $-0.21^{* *}$ & $0.19^{* *}$ & - & & & & & & \\
\hline \multicolumn{10}{|l|}{0 Non-pedophilic } \\
\hline \multicolumn{10}{|l|}{1 Pedophilic } \\
\hline Non-heterosexual Orientation (NO) ${ }^{b}$ & $-0.16^{*}$ & $0.16^{*}$ & -.02 & - & & & & & \\
\hline \multicolumn{10}{|l|}{0 Heterosexual } \\
\hline \multicolumn{10}{|l|}{1 non-heterosexual } \\
\hline Social Desirability (SD) & -0.10 & $0.17^{*}$ & $0.15^{*}$ & 0.02 & - & & & & \\
\hline Education $(E)^{b}$ & -0.00 & -0.06 & -0.09 & $0.15^{*}$ & -0.05 & - & & & \\
\hline \multicolumn{10}{|l|}{$\begin{array}{l}0 \text { Elementary, High school, some } \\
\text { college }\end{array}$} \\
\hline \multicolumn{10}{|l|}{$\begin{array}{l}1 \text { Associate and/or Bachelor's } \\
\text { degree, }\end{array}$} \\
\hline \multicolumn{10}{|l|}{$\begin{array}{l}\text { Master's degree, Doctorate or } \\
\text { pro-fessional degree, or other } \\
\text { advanced degree }\end{array}$} \\
\hline $\begin{array}{l}\text { Political Orientation ( } 1 \text { = conservative, } \\
10=\text { liberal; PO) }\end{array}$ & $-0.24^{* *}$ & 0.08 & 0.06 & 0.09 & 0.06 & -0.03 & - & & \\
\hline Children $(C)^{\mathrm{b}}$ & -0.05 & 0.09 & 0.01 & $0.15^{*}$ & $0.16^{*}$ & $-0.16^{*}$ & 0.01 & - & \\
\hline \multicolumn{10}{|l|}{0 has children } \\
\hline \multicolumn{10}{|l|}{1 has no children } \\
\hline $\begin{array}{l}\text { Offenses: Child pornography and/or } \\
\text { child abuse }(0)^{\text {b }}\end{array}$ & 0.01 & 0.07 & 0.09 & 0.09 & -0.03 & 0.01 & 0.00 & -0.02 & - \\
\hline \multicolumn{10}{|l|}{0 no conviction } \\
\hline \multicolumn{10}{|l|}{1 one or more convictions } \\
\hline Age & 0.05 & -0.01 & -0.02 & -0.07 & $-0.26^{* *}$ & $0.21^{* *}$ & -0.00 & $-0.42^{* *}$ & $0.31^{* *}$ \\
\hline
\end{tabular}

two-sided). On a side note, participant gender and age orientations were not statistically associated $\left(X^{2}=.04, p=.838\right)$. It is important to note that methodological limitations arise when recruiting from webforums that differentially attract people with restrictive moral attitudes towards adult child sex and different gender orientations; hence, these findings should be interpreted very cautiously.

Our one-item measure of political orientation also showed statistically significant associations with the Immoral Sex score but was not correlated to Representativeness Beliefs. The link between higher conservatism and more restrictive moral attitudes could be observed in both gender conditions $\left(r_{\text {spearman }}=-.24, p=.022\right.$ for girls, $r_{\text {spearman- }}$ $=-.21, p=.043$ for boys, all tests two-sided), and is therefore unlikely to reflect different moral norms regarding heterosexual vs. homosexual relationships among conservative participants. We found no indications that moral attitude ratings were tainted by social desirability bias (yet, note that Social Desirability showed a weak association with Representativeness Beliefs, see Table 3). We conducted further statistical tests to explore potential associations between the Immoral Sex scale, Representativeness Beliefs and sociodemographic data (age, having children below age 14, previous convictions for sexual offenses, education), but none of these achieved statistical significance (Table 3).

\section{Effects of gender and physical maturity, controlling for further variables}

To elucidate a clearer pattern of results, we conducted two analyses of covariance (ANCOVA) controlling for preferential pedophilia, non-heterosexual orientation, political 
Table 4. Immoral sex and representativeness beliefs depending on gender and maturity, controlling for potential confounding variables.

\begin{tabular}{|c|c|c|c|c|c|c|}
\hline \multirow[b]{2}{*}{ Variables and coding schemes } & \multicolumn{3}{|c|}{$\begin{array}{c}\text { ANCOVA test statistics for } \\
\text { Immoral Sex as outcome } \\
\text { variable }\end{array}$} & \multicolumn{3}{|c|}{$\begin{array}{l}\text { ANCOVA test statistics for } \\
\text { Representativeness Beliefs as } \\
\text { outcome variable }\end{array}$} \\
\hline & $F$ & $p$ & $\eta^{2}$ & $F$ & $p$ & $\eta^{2}$ \\
\hline Preferential pedophilia & 7.36 & .007 & .04 & 5.60 & .019 & .03 \\
\hline Non-heterosexual preference & 4.23 & .041 & .02 & 5.49 & .020 & .03 \\
\hline Social Desirability & 0.62 & .432 & .00 & 3.68 & .057 & .02 \\
\hline Political Orientation & 9.16 & .003 & .05 & 0.50 & .479 & .00 \\
\hline Gender (1 Female, 2 Male) & 2.37 & .125 & .01 & 4.49 & .036 & .03 \\
\hline Maturity (1 Pre-pubertal, 2 Pubertal) & 0.97 & .326 & .01 & 1.59 & .209 & .01 \\
\hline Gender x Maturity & 0.29 & .590 & .00 & 1.92 & .168 & .01 \\
\hline
\end{tabular}

Note: $d f 1=1, d f 2=172$ for Immoral Sex as outcome, $d f 2=175$ for Representativeness Beliefs as outcome.

orientation, and Social Desirability as variables that correlated with at least one of the two outcome variables of our experiment (see Table 4). Even when taking the effect of these variables into account, we still could not detect an effect of our central independent variables gender and physical maturity on Immoral Sex. However, we detected a significant effect of gender and Representativeness Beliefs. More specifically, engaging in sex with an adult man is judged to be more typical for boys than for girls. Note that a multivariate regression analysis incorporating the relevant interaction effects in order to exploit the full continuous potential of the sexual preference ratings (which have been dichotomized in all previous analyses) leads to similar findings regarding the main and combined effects of gender and sexual maturity (results available on request).

\section{Discussion}

Contrary to our expectations, the gender and physical maturity of the child did not have a significant impact on moral judgment. This means that participants did not see sex with physically immature or female children as more (or less) problematic than sex with more mature or male children, respectively. Also contradicting our previous hypotheses, gender and physical maturity of the child did not have a significant influence on Representativeness Beliefs, unless when controlling for confounding variables in an ANCOVA - then the sexual behavior as portrayed in the vignette is seen as more typical for boys than for girls. Hence, although sexual abuse of girls is statistically more common than sexual abuse of boys (Pereda, Guilera, Forns, \& Gómez-Benito, 2009a, 2009b), it appears as though pedophilic men perceive boys as more interested in sexual activity than girls, even in early pubertal stages. Furthermore, as expected, we found that a more liberal political orientation and a preference for prepubescent children (as opposed to hebephilic or teleiophilic categories) among pedophilic men were associated with less agreement with arguments against adult-child sex. This does not mean that liberal individuals in general are more likely than conservatives to express offense-supportive attitudes. Yet, liberal ideology may, in principle, be used to defend any unusual sexual contacts if (and only if) the sexual interaction can be construed as consensual and the actors as being capable of giving consent. A recent qualitative study found that pedohebephilic men often equate assent (which corresponds to the child willingly engaging in sexual activities without necessarily understanding their full meaning and consequences) and informed consent, when making moral judgements about the permissibility of adult-child sex (Spriggs et al., 2018). Hence, as pedophilic men 
are more likely to perceive adult-child sex as a harmless and fun activity between a caring adult and a presumably active and willing child partner, this might explain why liberalism is strongly linked to permissive attitudes towards adult-child sex among pedophilic men. We assume, however, that most nonpedophilic men would not agree that adult-child sex can ever be consensual, nonexploitative, or harmless, irrespective of whether they hold liberal and sex-positive attitudes in general.

Regarding physical maturity, we would speculate based on our data that most people in the Western world are now more accustomed to use age and not physical traits as the reference to make decisions about issues like the age of sexual consent. This does not necessarily mean that sexual maturity is not a relevant variable. For instance, comparing responses to children of different ages (e.g. a 7-year old vs. a 13-year old child) as opposed to children of the same age but with different levels of maturity might be more likely to produce large effects (but note that these children would differ in more respects than physical or sexual maturity, which would make it difficult to interpret such results). The child's gender variable on the other hand is also mostly absent in modern public discourses about sexual morality. Yet, while none of the provided commentaries suggested that physical maturity could be a relevant element for moral judgment, a number of comments involved ideas about the relevance of gender, both the adult's and the child's. Some added explicit opinions about the difference in sexuality between boys and girls; others wrote that they would have preferred to judge a scenario describing a minor of the other sex or describing a heterosexual or homosexual relationship, or said that 'boylovers' and 'boygirls' had a different approach to these experiences. This suggests that gender, probably of both the adult and the child, can be an interesting variable for future studies. Prior research indicates that there is a double sexual standard with regards to sexual experiences between adults and children, leading to different moral, or even legal, evaluations depending on whether the adult is a man or a woman and the child is a girl or a boy (Broussard et al., 1991). Such a difference might be more relevant for older children who show some level of physical maturity. Likewise, it would be interesting to investigate if non-heterosexual pedophilic men would continue to show more permissive attitudes towards adult-child sex when the adult is described as female.

In line with some previous findings among non-forensic samples of minor-attracted men (Bailey et al., 2016; Jahnke et al., 2017), we did not find a link between pro-offense attitudes and prior convictions for sexual offending against children. This non-association could be explained by a number of reasons, such as under-reporting of convictions or undetected offenses. Yet, due to the sensitive nature of this information, we cannot control for these factors without compromising survey ethics, anonymity, and participants' willingness to provide honest responses. It is also possible that attitudes have changed since the offense leading to the conviction, which may have occurred a long time ago. Nevertheless, forensic experts should also consider the possibility that previous research on offending populations has overestimated the importance of moral attitudes towards offending for the prediction of actual offending.

\section{Limitations}

To minimize the collection of data that could lead to de-identification, we only assessed a small number of personal variables and refrained from asking about recruitment source 
(e.g. Virtuous Pedophiles, BoyChat, or snowball sampling). Especially the latter decision leads to limitations with regards to the interpretation of some of our results, as some sites from which we recruited participants do not take any explicit position on whether adult-child sex is harmful or immoral (e.g. BoyChat), while others do so very strongly (e.g. Virtuous Pedophiles). Unfortunately, these sites are also likely to attract men who differ in their offending status and sexual gender orientation (e.g. BoyChat targeting men with a sexual interest in boys), as well as other potentially important variables. Therefore, our correlational findings pertaining to sexual gender orientation and its link to higher Immoral Sex scores cannot be interpreted with sufficient certainty. While we cannot rule out the possibility of other correlational findings (e.g. the non-association between Immoral Sex and prior offending) being affected, we see less potential for bias here. For instance, as we found that male-attracted pedophilic men were not more or less likely to have a hebephilic or teleiophilic preference (alongside pedophilic interests), the assumption that the different websites differentially attracted pedophilic men with different age orientations seems unlikely. Also, as participants were randomly assigned to vignette conditions, this limitation does not apply to our central hypotheses regarding the effects of child gender and physical maturity. Subsequent studies should nevertheless consider collecting information on the types of sites that pedophilic participants frequent as well as how they received the link to our survey, while carefully weighing the benefits and risks (e.g. in the case that e-mail lists are hacked or leaked). This would allow drawing more reliable conclusions regarding the links between sexual gender orientation and moral attitudes towards adult-child sex.

All results are based on self-report; therefore, they might be subject to a number of biases, including over- or underreporting, lying (e.g. about sociodemographic characteristics to further minimize the risk of identification), or social desirability bias. As we did not track IP addresses for anonymity reasons, we cannot rule out that some participants repeated the survey several times. Research on highly emotional, political, or controversial issues can also be biased by deliberate attempts to influence the results of the survey. As some pedophilic men might want to steer the public opinion towards being more accepting of adult-child sex, they may consider partaking in research to further these goals. However, as there is no clear responding pattern to produce the intended (or opposite) effect, we do not think that the results are biased by deliberate attempts to exaggerate or downplay moral attitudes towards adult-child sex. As social desirability scores were not associated with the agreement with moral arguments against adult-child sex and only weakly correlated with Representativeness Beliefs, we have good reasons to assume that pedophilic men in this sample were willing to give honest replies and trusted the anonymity of the online setting.

It is also important to point out that we recruited an ad hoc-sample that is not representative for pedophilic men. Pedophilic men involved in online communities for minor-attracted people are likely to differ from those who do not seek online contacts to other individuals with similar sexual attractions (e.g. they might have more need for affirmation or counseling, be more distressed or frustrated about their sexuality and the stigma attached to it, and/or simply have more free time to spare). Among pedophilic men from online communities, we would also expect differences between those who follow invitations to participate in research and those who decline (e.g. participants might have a higher trust in researchers than non-participants), so the results cannot be 
generalized to all pedophilic men who join online communities. Sociodemographic data suggests that the sample is biased towards younger and more educated participants, which is typical for online research (e.g. Alvarez, Sherman, \& VanBeselaere, 2003; Peer, Samat, Brandimarte, \& Acquisti, 2016). Also, even though some participants in this research had non-pedophilic preferences, all had to indicate at least a moderate sexual attraction to prepubescent children in order to participate. Hence, based on this research, we cannot know how hebephilic men with little to no sexual interest in prepubescent children would rate the presented scenes as opposed to pedophilic men.

Furthermore, studying moral evaluations based on vignettes might not reflect people's actual reactions and moral intuitions when faced with a real event or a real child. In a vignette scenario, the age of a child might be more salient for participants than physical maturation. Hence, future studies might consider adding pictures of the people involved in the sexual act.

\section{Conclusion and outlook}

The current social discourse on pedophilia and child sexual abuse tends to consider pedophilic adults as morally indifferent individuals who force or manipulate children to have sex with them. Findings from the current survey suggest that moral reasoning among pedophilic men is more diverse and rich than many might expect. As a partial replication of a previous survey among German-speaking pedohebephilic men (Jahnke et al., 2017), our results confirm some important findings and/or previous hypotheses: 1) the English version of the Immoral Sex scale has acceptable psychometric properties and seems appropriate for use especially in community samples of pedophilic men, 2) moral judgments between men with a pedophilic sexual orientation are not homogenous, as there exists a large minority who rejects adult-child sex, even when presented as not involving force or manipulation, 3) there is general agreement that the child would have to fear stigmatization from society due to his or her sexual activities with an adult, 4) preferential pedophilia and liberal political orientations appear to be linked to more permissive attitudes (but note that more research is needed to rule out recruitment bias as a potential alternative explanation), and 5) attitudes about the moral permissibility of adult-child sex appear to be unrelated to prior offending. Contrary to our expectations, the gender and sexual maturity of the child did not influence whether adult-child sex was perceived as immoral or whether the child's reaction was rated as believable or common, with the exception of boys being perceived as more likely to willingly engage in sex after controlling for covariates. Also, replicating observations from Jahnke et al.'s (2017) German study, English-speaking pedophilic participants in this survey did not seem to be able or willing to differentiate between different types of moral arguments against adult-child sex (as indicated by high intercorrelations between the subscales). While it is theoretically possible to endorse the argument that children cannot consent to sexual activities and disagree that it is always harmful (which resembles the way that Finkelhor, 1979 argues in his widely cited manuscript on the ethics of adult-child sex), this level of differentiation seems to be highly unusual among lay people.

For future research in this area, we have to keep in mind that aspects like gender and physical maturity are probably more salient and relevant when we are judging real dilemmas in everyday life. Judgments about sexual morality may be appraised based primarily 
on emotions or moral intuitions (Jahnke, 2018; Russell \& Piazza, 2015), which may depend less on reason or context information than on deep-seated values and preconceptions, on our ideals of masculinity/femininity and concepts of normal and deviant sexuality. This is also reflected in some of the commentaries we received at the end of the survey, where participants pointed out that they found it difficult to judge the presented fictitious scene. A few respondents also noted that some pieces of information that they perceived as critical were missing, especially regarding the type of relationship between the man and the child. Others suggested further potentially relevant aspects like the question who initiated the contact and if the child initially wanted it, the child's feelings and behaviors during the experience, whether both were aware of negative social attitudes regarding adult-child sex, whether the adult had a caring, child-centered attitude, and different characteristics of the child, such as his or her emotional intelligence and maturity, family and school life, and so on. Consequently, we see ample potential for future studies on how people with and without a sexual attraction to minors form a moral position regarding the moral permissibility of adult-child sex.

\section{Acknowledgements}

We thank Brittany Smelquist for her thorough copy editing.

\section{Disclosure statement}

No potential conflict of interest was reported by the authors.

\section{References}

Abel, G. G., Gore, D. K., Holland, C. L., Camp, N., Becker, J. V., \& Rathner, J. (1989). The measurement of the cognitive distortions of child molesters. Sexual Abuse: A Journal of Research and Treatment, 2(2), 135-152. doi:10.1177/107906328900200202.

Alvarez, R. M., Sherman, R. P., \& VanBeselaere, C. (2003). Subject acquisition for web-based surveys. Political Analysis, 11(1), 23-43. doi:10.1093/pan/11.1.23.

Back, S., \& Lips, H. M. (1998). Child sexual abuse: Victim age, victim gender, and observer gender as factors contributing to attributions of responsibility. Child Abuse \& Neglect, 22(12), 1239-1252. doi:10.1016/S0145-2134(98)00098-2.

Bailey, J. M., Bernhard, P. A., \& Hsu, K. J. (2016). An internet study of men sexually attracted to children: Correlates of sexual offending against children. Journal of Abnormal Psychology, 125(7), 989-1000. doi:10.1037/abn0000213.

Banse, R., Koppehele-Gossel, J., Kistemaker, L. M., Werner, V. A., \& Schmidt, A. F. (2013). Pro-criminal attitudes, intervention, and recidivism. Aggression and Violent Behavior, 18(6), 673-685. doi:10. 1016/j.avb.2013.07.024.

Beier, K. M. (2016). Proactive strategies to prevent child sexual abuse and the use of child abuse images: Experiences from the German Dunkelfeld project. In H. Kury, S. Redo, \& E. Shea (Eds.), Women and children as victims and offenders: Background, prevention, reintegration (pp. 499524). Basel: Springer International Publishing. doi:10.1007/978-3-319-28424-8_19

Beier, K. M., Ahlers, C. J., Goecker, D., Neutze, J., Mundt, I. A., Hupp, E., \& Schaefer, G. A. (2009). Can pedophiles be reached for primary prevention of child sexual abuse? First results of the Berlin prevention project Dunkelfeld (PPD). Journal of Forensic Psychiatry \& Psychology, 20(6), 851-867. doi:10.1080/14789940903174188.

Benn, P. (1999). Is sex morally special? Journal of Applied Philosophy, 16(3), 235-245. doi:10.1111/ $1468-5930.00126$. 
Broussard, S., \& Wagner, W. G. (1988). Child sexual abuse: Who is to blame? Child Abuse \& Neglect, 12 (4), 563-569. doi:10.1016/0145-2134(88)90073-7.

Broussard, S., Wagner, W. G., \& Kazelskis, R. (1991). Undergraduate students' perceptions of child sexual abuse: The impact of victim sex, perpetrator sex, respondent sex, and victim response. Journal of Family Violence, 6(3), 267-278. doi:10.1007/BF00980533.

Bruzzese, J.-M., \& Fisher, C. B. (2003). Assessing and enhancing the research consent capacity of children and youth. Applied Developmental Science, 7(1), 13-26. doi:10.1207/S1532480XADS0701_2.

Bullough, V. L., \& Bullough, B. (1994). Human sexuality: An encyclopedia. New York, NY: Garland Publishing.

Cohen, L., Ndukwe, N., Yaseen, Z., \& Galynker, I. (2017). Comparison of self-identified minor attracted persons who have and have not successfully refrained from sexual activity with children. Journal of Sex \& Marital Therapy. doi:10.1080/0092623X.2017.1377129.

Davis, M. (1983). Smut: Erotic reality/obscene ideology. Chicago, IL: University of Chicago Press.

Faul, F., Erdfelder, E., Lang, A.-G., \& Buchner, A. (2007). G*power 3: A flexible statistical power analysis program for the social, behavioral, and biomedical sciences. Behavior Research Methods, 39(2), 175-191.

Finkelhor, D. (1979). What's wrong with sex between adults and children? Ethics and the problem of sexual abuse. American Journal of Orthopsychiatry, 49(4), 692-697. doi:10.1111/j.1939-0025.1979. tb02654.x.

Fortenberry, J. D. (2013). Puberty and adolescent sexuality. Hormones and Behavior, 64(2), 280-287. doi:10.1016/j.yhbeh.2013.03.007.

Frayser, S. G. (1985). Varieties of sexual experience. An anthropological perspective on human sexuality. New Haven, Connecticut: HRAF Press.

Gannon, T. A., \& Polaschek, D. L. L. (2006). Cognitive distortions in child molesters: A re-examination of key theories and research. Clinical Psychology Review, 26(8), 1000-1019. doi:10.1016/j.cpr.2005. 11.010 .

Goode, S. D. (2009). Understanding and addressing adult sexual attraction to children: A study of paedophiles in contemporary society. New York, NY: Routledge.

Guerra, V. M., Gouveia, V. V., Sousa, D. M., Lima, T. J., \& Freires, L. A. (2012). Sexual liberalism-conservatism: The effect of human values, gender, and previous sexual experience. Archives of Sexual Behavior, 41(4), 1027-1039. doi:10.1007/s10508-012-9936-4.

Helmus, L., Hanson, R. K., Babchishin, K. M., \& Mann, R. E. (2013). Attitudes supportive of sexual offending predict recidivism: A meta-analysis. Trauma, Violence, \& Abuse, 14(1), 34-53. doi:10. $1177 / 1524838012462244$

Herdt, G., \& McClintock, M. (2000). The magical age of 10. Archives of Sexual Behavior, 29(6), 587-606. doi:10.1023/A:1002006521067.

Herek, G. M. (2004). Beyond "homophobia": Thinking about sexual prejudice and stigma in the twenty-first century. Sexuality Research \& Social Policy, 1(2), 6-24. doi:10.1525/srsp.2004.1.2.6.

Holt, T. J., Blevins, K. R., \& Burkert, N. (2010). Considering the pedophile subculture online. Sexual Abuse: A Journal of Research and Treatment, 22(1), 3-24. doi:10.1177/1079063209344979.

Howitt, D., \& Sheldon, K. (2007). The role of cognitive distortions in paedophilic offending: Internet and contact offenders compared. Psychology, Crime \& Law, 13(5), 469-486. doi:10.1080/ 10683160601060564.

Jahnke, S. (2018). Emotions and cognitions associated with the stigma of nonoffending pedophilia: A vignette experiment. Archives of Sexual Behavior, 47, 363-373.

Jahnke, S., Schmidt, A. F., Geradt, M., \& Hoyer, J. (2015). Stigma-related stress and its correlates among men with pedophilic sexual interests. Archives of Sexual Behavior, 44(8), 2173-2187. doi:10.1007/ s10508-015-0503-7.

Jahnke, S., Schmitt, S., \& Malón, A. (2017). What if the child appears to enjoy it? Moral attitudes toward adult-child sex among men with and without pedohebephilia. The Journal of Sex Research, 1-12. doi:10.1080/00224499.2016.1271101.

Killias, M. (2000). The emergence of a new taboo: The desexualisation of youth in Western societies since 1800. European Journal on Criminal Policy and Research, 8(4), 459-477. doi:10.1023/ A:1008792013662. 
Kuther, T. L. (2003). Medical decision-making and minors: Issues of consent and assent. Adolescence, 38(150), 343-358.

Leiner, D. J. (2014). SoSci Survey (Version 2.5.00 - i). Retrieved from https://www.soscisurvey.de

Malón, A. (2015). Adult-child sex and the limits of liberal sexual morality. Archives of Sexual Behavior, 44(4), 1071-1083. doi:10.1007/s10508-014-0442-8.

Malón, A. (2017). Adult-child sex and the demands of virtuous sexual morality. Sexuality \& Culture, 21(1), 247-269. doi:10.1007/s12119-016-9392-8.

Marks, M. J., \& Fraley, R. C. (2005). The sexual double standard: Fact or fiction? Sex Roles, 52(3-4), 175-186. doi:10.1007/s11199-005-1293-5.

Marshall, W. A., \& Tanner, J. M. (1969). Variations in pattern of pubertal changes in girls. Archives of Disease in Childhood, 44(235), 291-303.

Marshall, W. A., \& Tanner, J. M. (1970). Variations in the pattern of pubertal changes in boys. Archives of Disease in Childhood, 45(239), 13-23. doi:10.1136/adc.45.239.13.

Murphy, W. D. (1990). Assessment and modification of cognitive distortions in sex offenders. In Handbook of sexual assault (pp. 331-342). Boston, MA: Springer. doi:10.1007/978-1-4899-09152_19.

Peer, E., Samat, S., Brandimarte, L., \& Acquisti, A. (2016). Beyond the Turk: An empirical comparison of alternative platforms for crowdsourcing online behavioral research (SSRN Scholarly Paper No. ID 2594183). Rochester, NY: Social Science Research Network. Retrieved from https://papers.ssrn. com/abstract $=2594183$

Pereda, N., Guilera, G., Forns, M., \& Gómez-Benito, J. (2009a). The international epidemiology of child sexual abuse: A continuation of Finkelhor (1994). Child Abuse \& Neglect, 33(6), 331-342. doi:10. 1016/j.chiabu.2008.07.007.

Pereda, N., Guilera, G., Forns, M., \& Gómez-Benito, J. (2009b). The prevalence of child sexual abuse in community and student samples: A meta-analysis. Clinical Psychology Review, 29(4), 328-338. doi:10.1016/j.cpr.2009.02.007.

Ray, J. J. (1984). The reliability of short social desirability scales. Journal of Social Psychology, 123(1), 133-134.

Russell, P. S., \& Piazza, J. (2015). Consenting to counter-normative sexual acts: Differential effects of consent on anger and disgust as a function of transgressor or consenter. Cognition and Emotion, 29(4), 634-653. doi:10.1080/02699931.2014.930420.

Schmidt, G. (2002). The dilemma of the male pedophile. Archives of Sexual Behavior, 31(6), 473-477. doi:10.1023/A:1020651130148.

Seidman, S. (1992). Embattled eros: Sexual politics and ethics in contemporary America. New York, NY: Routledge.

Seto, M. C. (2007). Pedophilia and sexual offending against children: Theory, assessment, and intervention (1st ed.). Washington, DC: American Psychological Association.

Spriggs, S. A., Cohen, L. J., Valencia, A., Zimri, Y. S., \& Galynker, I. I. (2018). Qualitative analysis of attitudes toward adult-child sexual activity among minor-attracted persons. Journal of Sex \& Marital Therapy, 2, 1-12. doi:10.1080/0092623X.2018.1474406.

Stermac, L. E., \& Segal, Z. V. (1989). Adult sexual contact with children: An examination of cognitive factors. Behavior Therapy, 20(4), 573-584. doi:10.1016/S0005-7894(89)80135-2.

Sun, S. S., Schubert, C. M., Chumlea, W. C., Roche, A. F., Kulin, H. E., Lee, P. A., ... Ryan, A. S. (2002). National estimates of the timing of sexual maturation and racial differences among US children. Pediatrics, 110(5), 911-919. doi:10.1542/peds.110.5.911.

Ward, T., \& Fortune, C.-A. (2016). From dynamic risk factors to causal processes: A methodological framework. Psychology, Crime \& Law, 22(1-2), 190-202. doi:10.1080/1068316X.2015.1117080.

Ward, T., \& Keenan, T. (1999). Child molesters' implicit theories. Journal of Interpersonal Violence, 14(8), 821-838. doi:10.1177/088626099014008003.

Ward, T., \& Siegert, R. J. (2002). Toward a comprehensive theory of child sexual abuse: A theory knitting perspective. Psychology, Crime \& Law, 8(4), 319-351. doi:10.1080/10683160208401823. 


\section{Appendix}

\section{Self-reported pedophilic, hebephilic, and teleiophilic interests}

Instruction: How strong is your sexual attraction to people of different genders and levels of physical maturity?

Items (to be rated on a scale from 1 [no sexual interest] to 10 [maximum sexual interest]):

(1) Boys before puberty (i.e. boys who show no signs of physical maturity, like pubic hair or a larger penis or scrotum)

(2) Girls before puberty (i.e. girls who show no signs of physical maturity, like pubic hair or budding breasts)

(3) Boys in early to mid-puberty (i.e. boys who show some signs of physical maturity, like sparse pubic hair or a slightly larger penis or scrotum compared to younger boys)

(4) Girls in early to mid-puberty (i.e. girls who show some signs of physical maturity, like sparse pubic hair or developing breasts)

(5) Adult men after puberty (i.e. physically mature men)

(6) Adult women after puberty (i.e. physically mature women)

\section{Vignette: pre-pubertal girl}

An 11-year old girl has sexual contact with an adult man who is aware of the girl's young age. The girl shows no signs of physical maturity, like pubic hair or breast buds, and does not look like an adult woman at all. They kiss, fondle, and touch each other's genitals. The adult does not use physical violence, threats, or money to make the girl participate in these actions, and repeatedly asks her permission before going on. Afterwards, the girl spontaneously tells the adult that she has enjoyed the experience.

\section{Vignette: early to mid-pubertal girl}

An 11-year old girl has sexual contact with an adult man who is aware of the girl's young age. The girl shows some signs of physical maturity, like a sparse growth of pubic hair and developing breasts, but does not yet look like an adult woman. They kiss, fondle, and touch each other's genitals. The adult does not use physical violence, threats, or money to make the girl participate in these actions, and repeatedly asks her permission before going on. Afterwards, the girl spontaneously tells the adult that she has enjoyed the experience.

\section{Vignette: pre-pubertal boy}

An 11-year old boy has sexual contact with an adult man who is aware of the boy's young age. The boy shows no signs of physical maturity, like pubic hair or a larger penis or scrotum compared to younger boys, and does not look like an adult man at all. They kiss, fondle, and touch each other's genitals. The adult does not use physical violence, threats, or money to make the boy participate in these actions, and repeatedly asks his permission before going on. Afterwards, the boy spontaneously tells the adult that he has enjoyed the experience.

\section{Vignette: early to mid-pubertal boy}

An 11-year old boy has sexual contact with an adult man who is aware of the boy's young age. The boy shows some signs of physical maturity, like a sparse growth of pubic hair and a slightly larger penis compared to younger boys, but does not yet look like an adult man. They kiss, fondle, and touch each other's genitals. The adult does not use physical violence, threats, or money to make the boy participate in these actions, and repeatedly asks his permission before going on. Afterwards, the boy spontaneously tells the adult that he has enjoyed the experience. 